\title{
PKM PANTI ASUHAN AS-SALAM "OPTIMALISASI KESEHATAN REPRODUKSI REMAJA MELALUI PENDAMPINGAN JACARE (REMAJA CARE)” TAHUN 2021
}

\author{
${ }^{1)}$ Dwi Sapta Aryantiningsih, ${ }^{2)}$ Linda Suryani \\ ${ }^{1)}$ Program Studi S1 Ilmu Kesehatan Masyarakat STIKes Payung Negeri Pekanbaru \\ ${ }^{2)}$ Program Studi S1 Kebidanan STIKes Payung Negeri Pekanbaru \\ 1,2) Jl. Tamtama No 06 Pekanbaru - Riau - Indonesia \\ E-Mail : dwisapta.aryantiningaih@payungnegeri.ac.id,linda.suryani@payungnegeri.ac.id
}

\begin{abstract}
ABSTRAK
Kesehatan reproduksi remaja sangat penting diperhatikan karena akibatnya sangat luas. Salah satu akibat kurang nya remaja memperhatikan kesehatan reproduksi adalah banyak ditemukan remaja yang mengalami infeksi pada organ reproduksi khususnya pada alat kelamin. Hanya $21,6 \%$ remaja yang melakukan perilaku personal hygiene dengan benar, dan 28\% remaja yang mendapatkan informasi tentang PIK-Remaja (Pusat Informasi dan konseling Remaja) berkaitan dengan kesehatan reproduksi. Seorang remaja perlu mendapatkan pendampingan supaya mendapatkan informasi yang benar sehingga masalah pada kesehatan seksual dan reproduksi tidak terjadi. Pendidikan teman sebaya akan berdampak terhadap peningkatan pengetahuan, sikap dan tindakan seseorang dalam menjaga kebersihan diri. Adapun tujuan pengabdian masyarakat ini yaitu agar permasalahan seputar kesehatan reproduksi remaja dapat diatasi dan adanya ruang diskusi dengan teman sebaya yang dikenal dengan remaja care (Jacare) untuk membahas masalah kesehatan reproduksi. Metode pelaksanaan kegiatan PKM secara garis besar meliputi tahapan pelatihan, pembentukan Jacare, pendampingan serta evaluasi. Setelah pemberian edukasi dan pembentukan Jacare sebagai wadah pendampingan bagi anak panti serta proses pendampingan maka diperoleh dampak positif yaitu adanya peningkatan pengetahuan dan keterampilan anak Panti As-Salam tentang kesehatan reproduksi. Kegiatan pendampingan yang dilakukan Jacare dapat membantu anak asuh menemukan solusi dari masalah kesehatan yang dihadapi. Oleh karena itu, perlu dilakukan pendampingan berkelanjutan terhadap anak panti untuk mengatasi masalah yang dihadapinya.
\end{abstract}

Kata Kunci: Kesehatan Reproduksi, Remaja, Pendampingan

\section{ABSTRACT}

Adolescent reproductive health is very important to pay attention to because the consequences are very broad. One of the consequences of the lack of attention to reproductive health by adolescents is that many adolescents are found to have infections in the reproductive organs, especially the genitals. Only $21.6 \%$ of adolescents carried out personal hygiene behavior correctly, and $28 \%$ of adolescents who received information about PIK-Remaja (Adolescent Information and Counseling Center) related to reproductive health. A teenager needs to get assistance in order to get the right information so that problems with sexual and reproductive health do not occur. Peer education will have an impact on increasing one's knowledge, attitudes and actions in maintaining personal hygiene. The purpose of this community service is so that problems around adolescent reproductive health can be resolved and there is a discussion room with peers known as adolescent care (Jacare) to discuss reproductive health problems. The method of implementing PKM activities in outline includes the stages of training, forming Jacare, mentoring and evaluation. After providing education and establishing Jacare as a forum for assistance for orphanage children and the mentoring process, a positive impact was obtained, namely an increase in the knowledge and skills of the As-Salam Orphanage children regarding reproductive health. Assistance activities carried out, made the children of the orphanage express the problems they were facing to Jacare so that the problems faced could be resolved. Therefore, it is necessary to provide ongoing assistance to orphanage children to overcome the problems they face.

Keyword: Reproductive Health, Adolescents, Mentoring

\section{PENDAHULUAN}

Masa remaja merupakan saat dimana seseorang mulai pertama kali menunjukkan pertumbuhan tanda-tanda seksual sekunder sampai mencapai pertumbuhan sempurna. Masa remaja disebut juga masa puberitas, pada remaja perempuan dicirikan dengan datangnya haid / menstruasi, sedangkan pada laki-laki mengalami mimpi basah. Pada masa ini terjadi perkembangan seksual dimana organ reproduksi terbentuk dengan sempurna, sehingga perlu diperhatikan kebersihan diri (personal hygiene) terutama kesehatan reproduksi [1]. 
Perilaku personal hygiene yang baik dan benar sangat penting, karena akan berpengaruh terhadap kesehatan seseorang [2]. Personal hygiene merupakan salah satu cara menjaga kebersihan dan kesehatan seseorang, untuk melindungi kesejahteraan fisik dan psikis. Remaja yang menerapkan pola hidup yang sehat, akan menjadi remaja yang sehat jasmani dan rohani [3]. Kesehatan reproduksi remaja sangat penting diperhatikan karena akibatnya sangat luas. Salah satu akibat kurang nya remaja memperhatikan kesehatan reproduksi adalah banyak ditemukan remaja yang mengalami infeksi pada organ reproduksi khususnya pada alat kelamin/alat genetalia [4].

Cara pemerintah mengatasi masalah kesehatan reproduksi pada remaja dengan menetapkan kesehatan reproduksi remaja sebagai program pemerintah. Pelayanan kesehatan reproduksi remaja dilakukan dalam rangka mempersiapkan remaja untuk dapat hidup sehat dan bertanggung jawab khususnya berkaitan dengan kesehatan reproduksinya. Pelayanan kesehatan reproduksi remaja dilakukan dengan menyesuaikan masalah yang dihadapi remaja dan tahapan tumbuh kembangnya serta tetap memperhatikan keadilan dan kesetaraan gender, mempertimbangkan nilai moral, agama, perkembangan mental, dan berdasarkan ketentuan peraturan perundang-undangan. [5].

Menurut Survei Demografi dan Kesehatan Indonesia (SDKI) tahun 2017 secara nasional hanya $21,6 \%$ remaja yang melakukan perilaku personal hygiene dengan benar, dan $28 \%$ remaja yang mendapatkan informasi tentang PIK-Remaja (Pusat Informasi dan konseling Remaja) berkaitan dengan kesehatan reproduksi [6].

Seorang remaja perlu mendapatkan pendampingan supaya mendapatkan informasi yang benar sehingga masalah pada kesehatan seksual dan reproduksi tidak terjadi. Informasi berkaitan dengan personal hygiene dapat diperoleh dari petugas kesehatan, keluarga, sekolah, lingkungan ataupun dari teman sebaya [7]. Informasi dari teman sebaya (peer education) merupakan bentuk informasi yang diberikan oleh seseorang yang berada dalam masa remaja atau mahasiswa (remaja akhir), dimana remaja tersebut berfungsi memberikan motivasi kepada remaja yang lain, seseorang yang tergabung dalam kelompok teman sebaya biasanya telah mengikuti pelatihan pendidikan sebaya. $[8]$.

Hasil penelitian didapatkan pendidikan teman sebaya mempengaruhi pengetahuan, sikap dan tindakan santri dalam menjaga kebersihan diri, dimana Ada perbedaan tingkat pengetahuan, sikap dan tindakan antara kelompok kontrol dan kelompok intervensi dengan pendidikan sebaya tentang menjaga kebersihan diri. Kelompok intervensi mengalami peningkatan yang lebih tinggi daripada kelompok kontrol [9].

Mitra dalam kegiatan ini adalah Panti asuhan As Salaam Nur Hidayah yang berada di Jl. Safari Gg. Safari IV Nomor 5 Kel. Labuhbaru Barat Kec. Payung Sekaki Kota Pekanbaru.. Jumlah anak asuh yang ada di Panti Asuhan As Salaam berjumlah 19 orang yang terdiri dari 8 orang perempuan dan 11 orang laki-laki. Anak asuh yang ada di panti jarang mendapatkan pembinaan berkaitan dengan kesehatan reproduksi. Ruang diskusi untuk berbincang tentang kesehatan reproduksi dengan teman sebaya juga tidak tersedia, dikarenkan adanya perasaan tabu dan sensitif untuk dibicarakan. Apabila anak asuh remaja memiliki permasalahan seputar kesehatan reproduksi maka penjelasannya hanya mereka dapatkan dari media sosial. Hal ini tentu saja tidak dapat dijamin kebenaran dan keakuratan informasinya. Masalah kesehatan reproduksi remaja yang umum terjadi yaitu dismenorea, keputihan, infeksi daerah genitalia, bau badan, dan ketombe. Dalam rangka mengatasi masalah yang dihadapi anak panti berkaitan dengan personal hygiene, maka pendekatan terapi peer group sangat tepat dipilih. 
Memberikan informasi dengan pembentukan kelompok belajar merupakan suatu cara yang efektif dalam memberikan informasi kepada remaja melalui lingkungan sosial sebayanya mengingat bahwa secara psikologis remaja lebih gampang terbuka dan berkomunikasi dengan teman seumurannya, selain itu, pemberian informasi melalui teman sebaya dapat meningkatkan pengetahuan remaja [10]. Kelompok sebaya memiliki dampak yang besar dalam kehidupan remaja, dimana adanya hubungan saling percaya antar teman sebaya, sehingga biasanya seorang remaja lebih percaya dan terbuka terhadap teman sebaya dibandingkan dengan orang tuanya [11]. Adapun tujuan pengabdian masyarakat ini yaitu agar permasalahan seputar kesehatan reproduksi remaja dapat diatasi, adanya ruang diskusi dengan teman sebaya untuk membahas masalah kesehatan reproduksi.

\section{METODE PELAKSANAAN}

Tahapan yang dilaksanakan dalam kegiatan PKM ini secara garis besar meliputi tahapan pelatihan, pelaksanaan serta evaluasi. Adapun uraian tahapan dalam pelaksanan PKM sebagai berikut :

Tahap pertama : Pengabdian Kepada Masyarakat ini dimulai dari pengurusan surat tugas melakukan pengabdian masyarakat dari STIKes Payung Negeri ke Panti Asuhan As-Salam. Setelah mendapatkan surat tugas untuk melakukan pengabdian masyarakat Tim PKM melakukan koordinasi dengan pengurus panti untuk pelaksanaan pengabdian masyarakat di Panti Asuhan AsSalam. Setelah mendapatkan ijin melakukan pengabdian masyarakat, tim PKM melakukan identifikasi terhadap masalah yang dialami anak panti berkaitan dengan kesehatan reproduksi khususnya mengenai personal hygiene, seks dan narkoba.

Tahap kedua: Setelah ditemukan permasalahan seputar anak asuh oleh tim PKM, maka selanjutnya berkoordinasi dengan pihak pengelola panti untuk menyusun rencana mengatasi permasalahan tersebut. Dalam hal ini rencana yang akan dijalankan yaitu melakukan pelatihan personal higiene, pelatihan Jacare, dan pendampingan anak asuh dan evaluasi program PKM.

Tahap ketiga: Melakukan pelatihan personal higiene yang bertujuan untuk meningkatkan pengetahuan anak asuh akan kesehatan reproduksi dan kebersihan dirinya. Peningkatan pengetahuan ini dilakukan dengan pemberian informasi kesehatan Kegiatan pelatihan ini dilaksanakan melalui penyuluhan meliputi konsep personal hygiene, indikator kesehatan, cara pencegahan, perawatan diri serta penyakit seputar kesehatan reproduksi dan praktikum kebersihan genitalia dan cara membersihkan gigi dengan menggunakan phantom (alat peraga). Dalam hal ini pelaksanaannya diberikan secara terpisah antara anak asuh putra dan putri.

Tahap keempat: Melakukan pembentukan dan pelatihan Remaja Care (Jacare). Remaja Care yaitu suatu upaya dari teman sebaya yang terdiri dari mahasiswa kesehatan (kesehatan masyarakat dan kebidanan) yang bertugas sebagai teman sebaya untuk bertukar informasi terkait masalah kesehatan reproduksi remaja, seks dan narkoba pada anak asuh. Pada kegiatan ini Jacare dibentuk dari 2 orang mahasiswa/i kesehatan. Selanjutnya Jacare ini diberikan pelatihan mengenai Peer Education (pendidikan sebaya). Pelatihan Jacare dilakukan sebanyak 6 kali pertemuan.

Tahap kelima: Melakukan pendampingan. Tim Remaja Care (Jacare) yang sudah dibentuk dan dilatih melakukan pendampingan kepada anak asuh yang ada di Panti Asuhan As-Salam.

Tahap keenam : Melakukan evaluasi pada setiap tahap kegiatan. Tim PKM melakukan pengukuran efektifitas pelatihan personal higiene. Pengukuran dilakukan kepada seluruh anak asuh yang mengikuti pelatihan melalui penyebaran kuesioner. 


\section{Kerangka Kerja Pengabdian}

Kerangka kerja kegiatan seperti pada gambar 1 berikut ini:

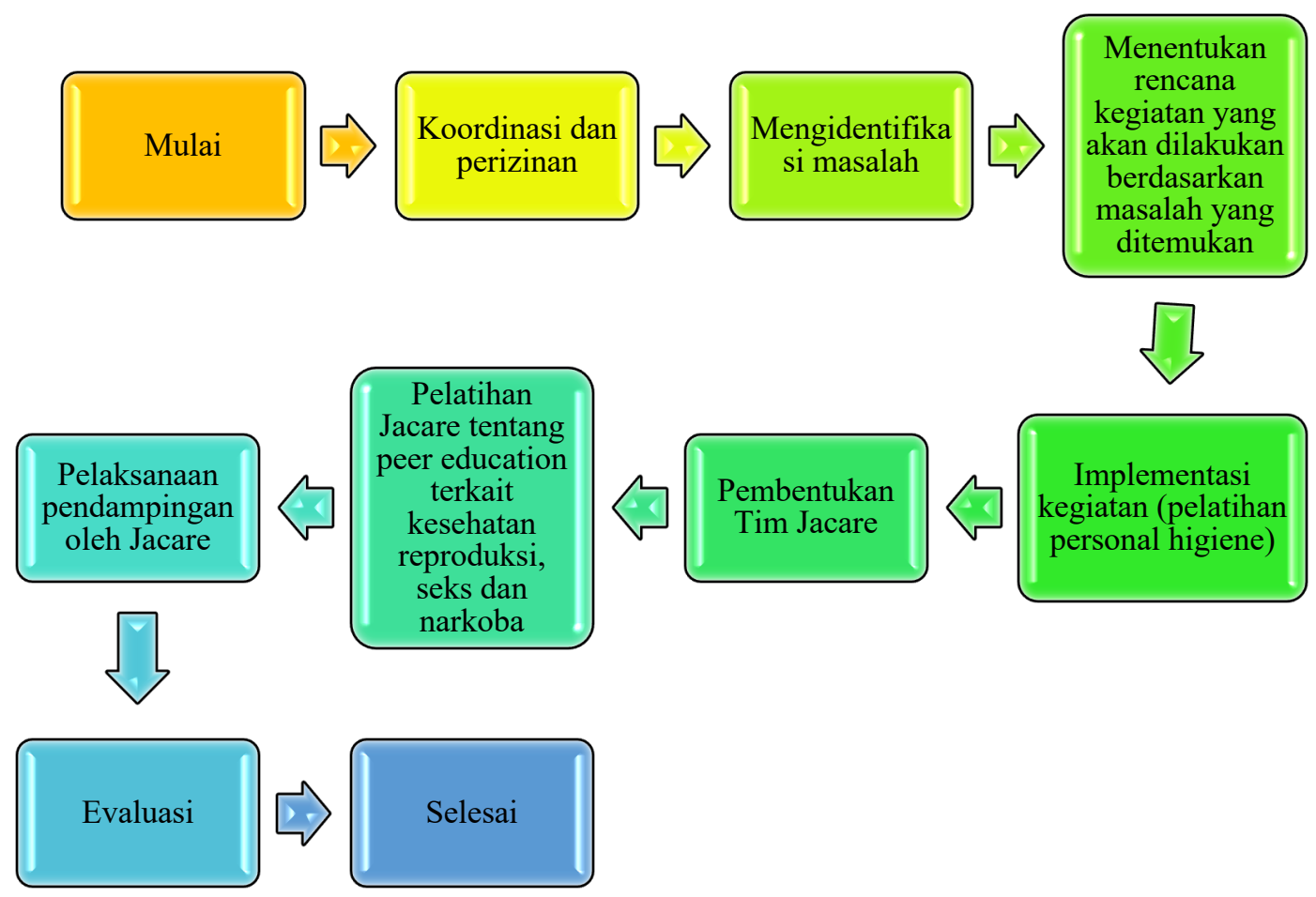

Gambar 1. Kerangka Kerja Kegiatan Pengabdian

\section{HASIL}

Hasil kegiatan Pengabdian Kepada Masyarakat di Panti asuhan As-Salam dapat dijabarkan sebagai berikut:

\section{Kegiatan Persiapan}

Kegiatan pengabdian masyarakat dimulai dengan pengurusan surat tugas melakukan pengabdian masyarakat dari STIKes Payung Negeri ke Panti Asuhan As-Salam. Setelah mendapatkan surat tugas untuk melakukan pengabdian masyarakat Tim PKM melakukan koordinasi dengan pengurus panti untuk pelaksanaan pengabdian masyarakat di Panti Asuhan As-Salam dan membahas jadwal pelaksanaan kegiatan pengabdian masyarakat. Setelah mendapatkan ijin melakukan pengabdian masyarakat, tim PKM melakukan identifikasi terhadap masalah yang dialami anak panti berkaitan dengan kesehatan reproduksi khususnya mengenai personal hygiene, seks dan narkoba.

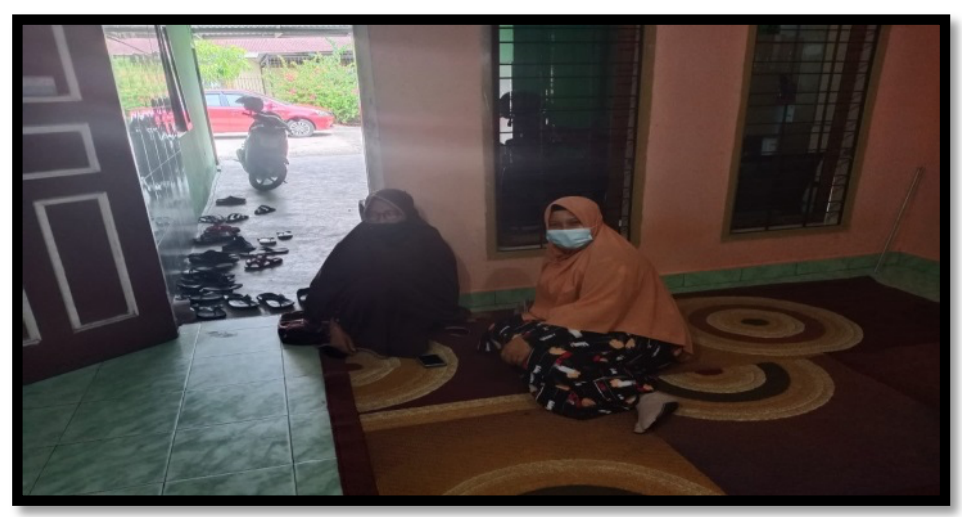




\section{Kegiatan Pelaksanaan}

Kegiatan pelaksanaan pengabdian masyarakat dimulai dengan melakukan:

1. Pertemuan dengan anak-anak panti asuhan As-salam untuk perkenalan oleh tim pengabdian masyarakat di Panti Asuhan As-Salam. Pada kegiatan ini TIM pengabdian masyarakat menjelaskan maksud dan tujuan dari TIM melakukan pengabdian masyarakat di panti asuhan
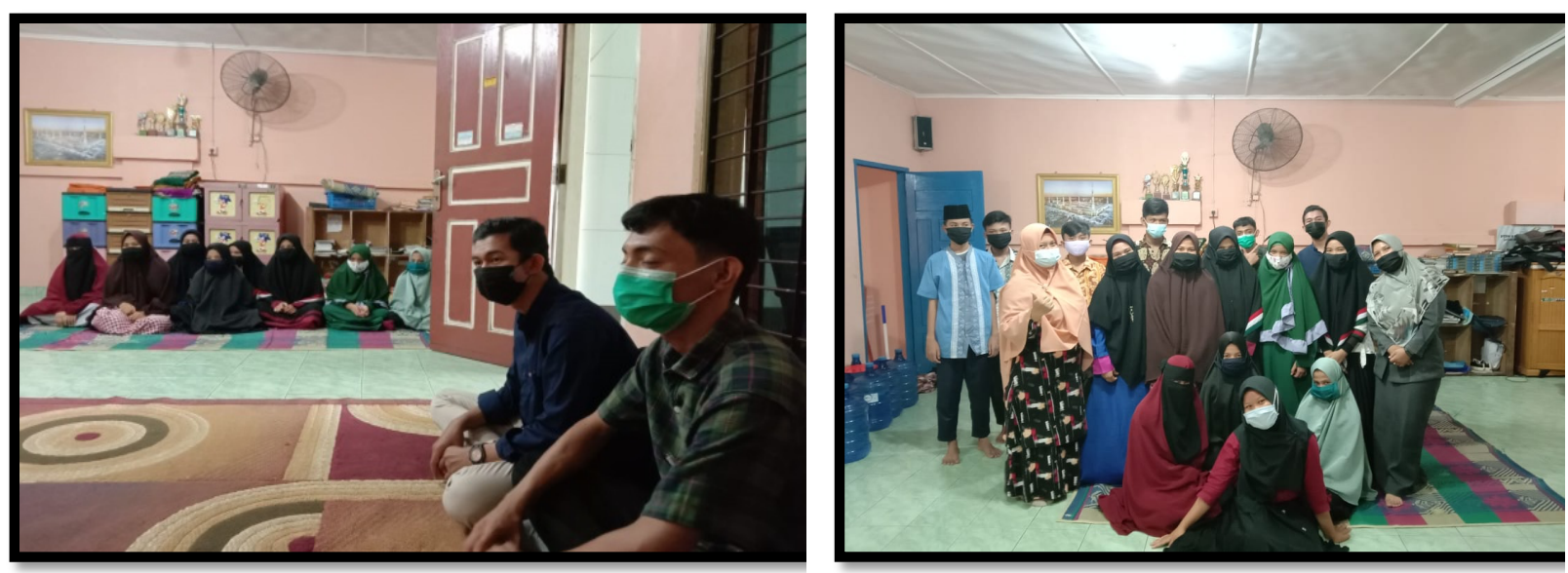

2. Pertemuan dengan anak asuhan panti asuhan As-Salam untuk melakukan analisis situasi dan mengidentifikasi masalah yang dialami oleh anak-anak panti. Pada kegiatan ini anakanak panti dibuat dalam beberapa kelompok, dimana kelompok dibuat berdasarkan jenis kelamin. Tim PKM mengajak anak-anak panti berbicara dan berdiskusi tentang masalah yang mereka alami khususnya berkaitan dengan kesehatan reproduksi. Hasil dari diskusi tersebutlah akan didapatkan gambaran masalah yang dihadapi anak panti
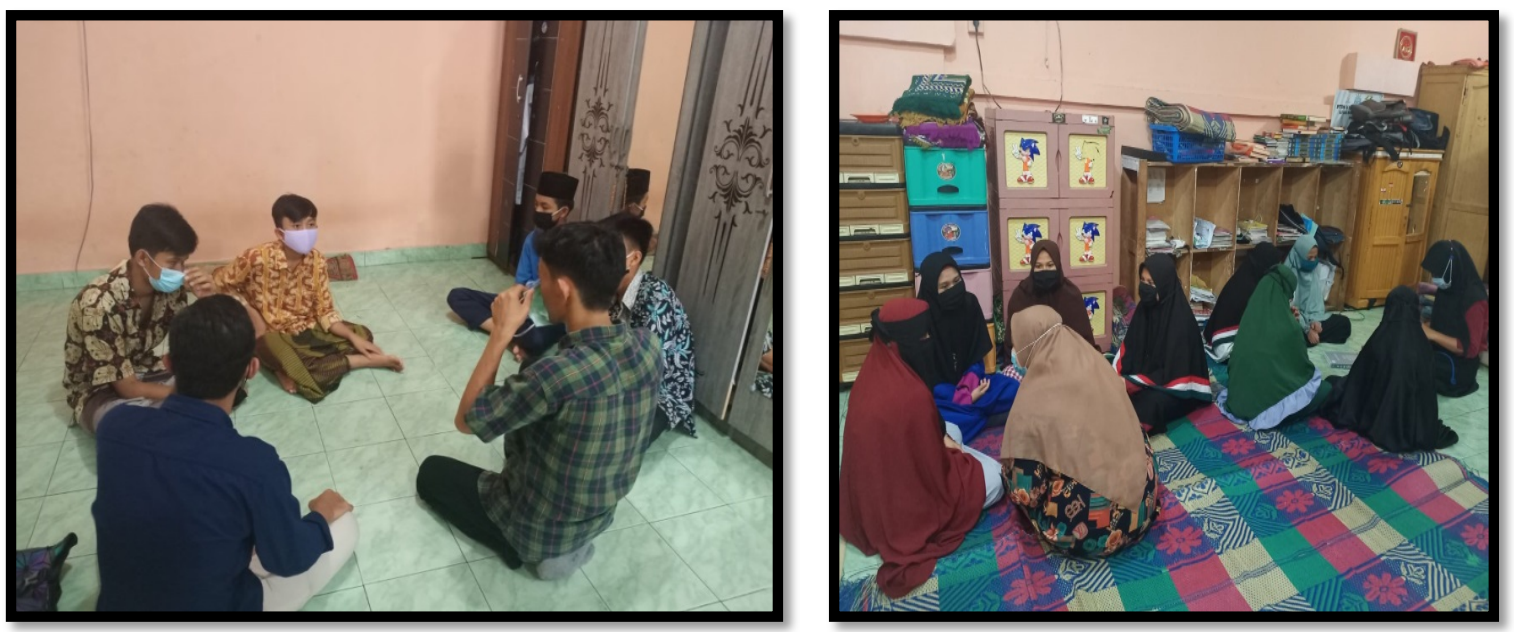

Gambar 2. Kerangka Kerja Kegiatan Pengabdian

3. Pertemuan dengan tim pengabmas terkait rencana kegiatan yang akan dilakukan berdasarkan masalah yang ditemukan. Pada kegiatan ini Tim PKM menjelaskan masalahmasalah yang mereka temukan pada saat dilakukan diskusi bersama anak panti 
sebelumnya. Dari masalah-masalah yang ditemukan, Tim membuat rencana tindak lanjut dalam mengatasi masalah yang ditemukan

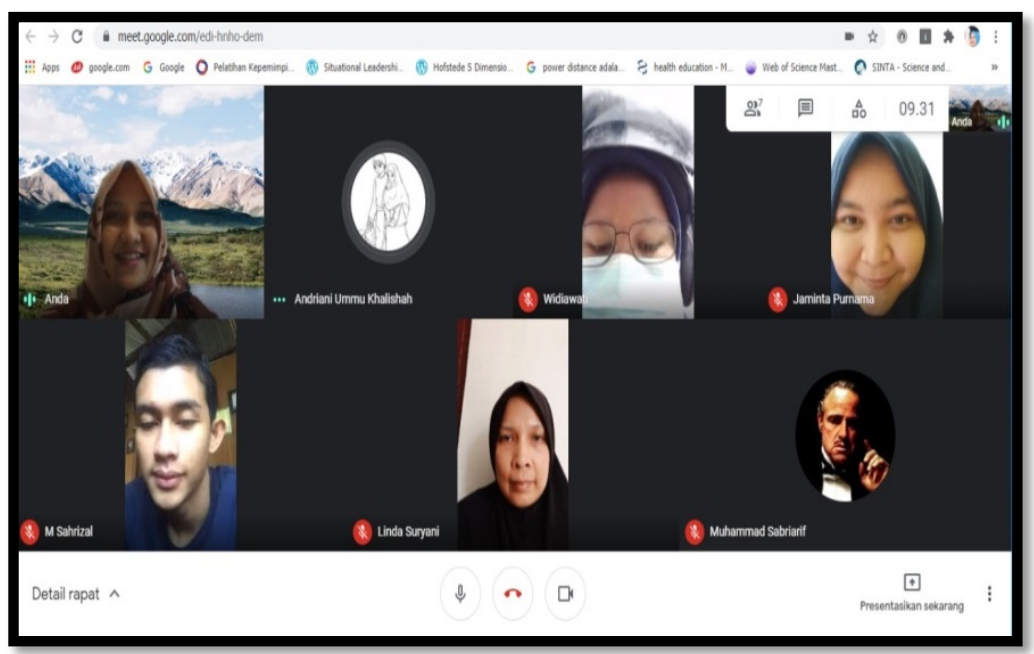

Gambar 3. Online meeting

4. Pelatihan personal hygiene pada anak panti asuhan. Pada kegiatan ini Tim PKM memberikan pelatihan yang dilaksanakan melalui penyuluhan, penyuluhan dilakukan berpisah antara anak asuh laki-laki dan perempuan, supaya materi yang disampaikan lebih spesifik kepada masalah yang sering ditemukan baik pada anak laki-laki maupun pada anak perempuan. Adapun topik penyuluhan meliputi konsep personal hygiene, indikator kesehatan, cara pencegahan, perawatan diri serta penyakit seputar kesehatan reproduksi baik pada laki-laki maupun pada perempuan. Sebelum melakukan penyuluhan anak-anak terlebih dahulu diberikan soal berkaitan dengan personal hygiene, pre test dilakukan dengan tujuan mengetahui pengetahuan awal anak panti berkaitan dengan personal hygiene.

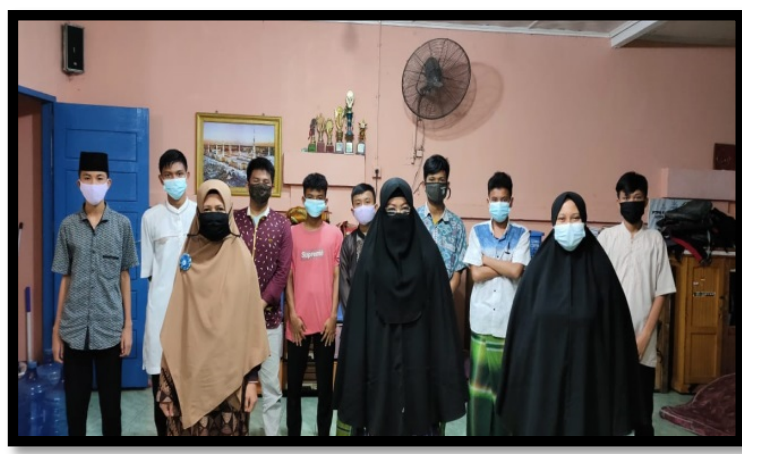

Penyuluhan kesehatan Pada kelompok anak laki-laki

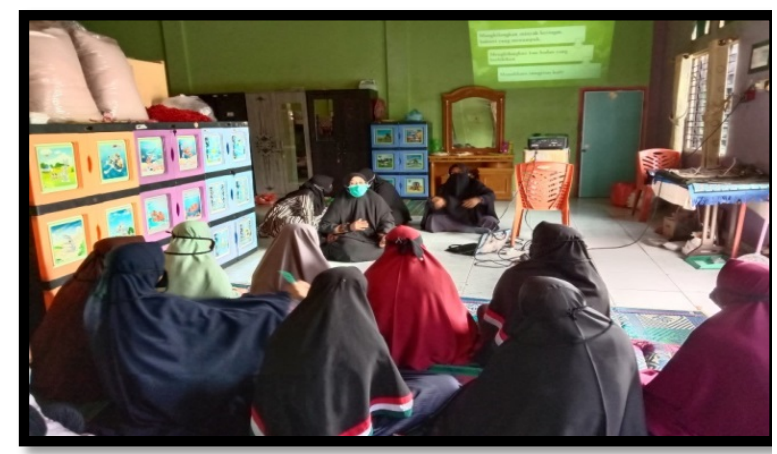

Penyuluhan kesehatan Pada kelompok anak perempuan

\section{Gambar 4. Penyuluhan kesehatan Pada kelompok anak laki-laki dan perempuan}

5. Praktikum kebersihan genitalia dengan menggunakan phantom (alat peraga). Pada kegiatan pelatihan ini Tim PKM memberikan pelatihan secara terpisah antara anak asuh laki-laki dan perempuan, supaya dalam melakukan praktek anak-anak lebih jelas, mengerti , tidak ada merasa malu karena tidak ada lawan jenis didalam ruangan tersebut, dan lebih spesifik kepada masalah yang sering ditemukan 

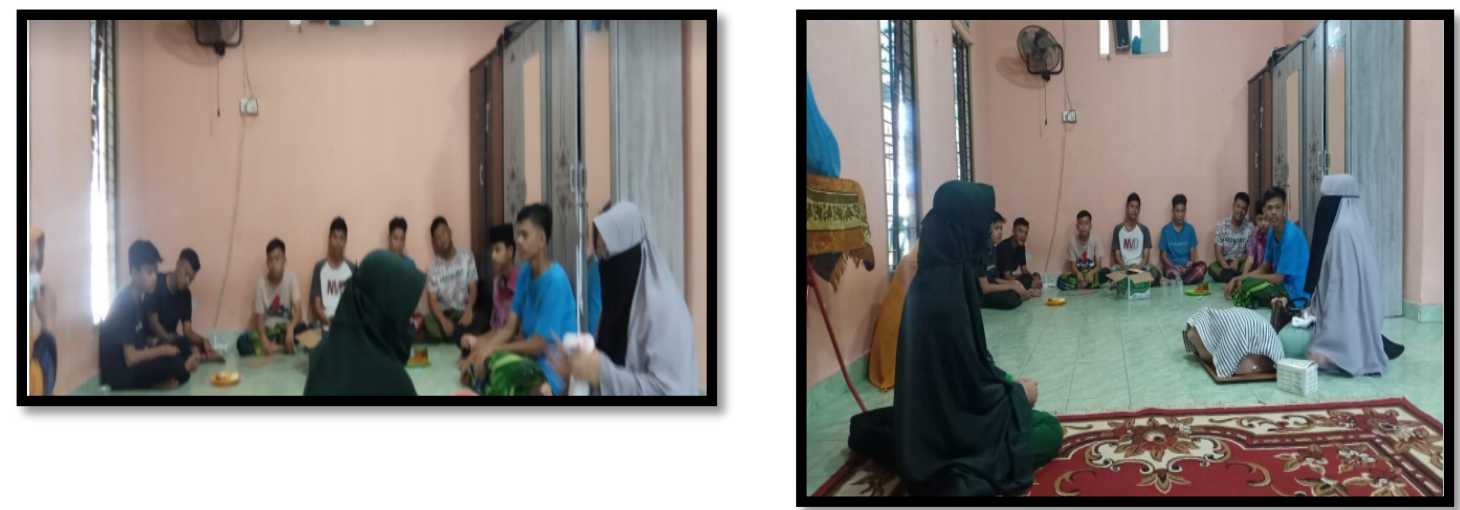

Gambar 5. Praktikum Personal Hygiene pada laki-laki
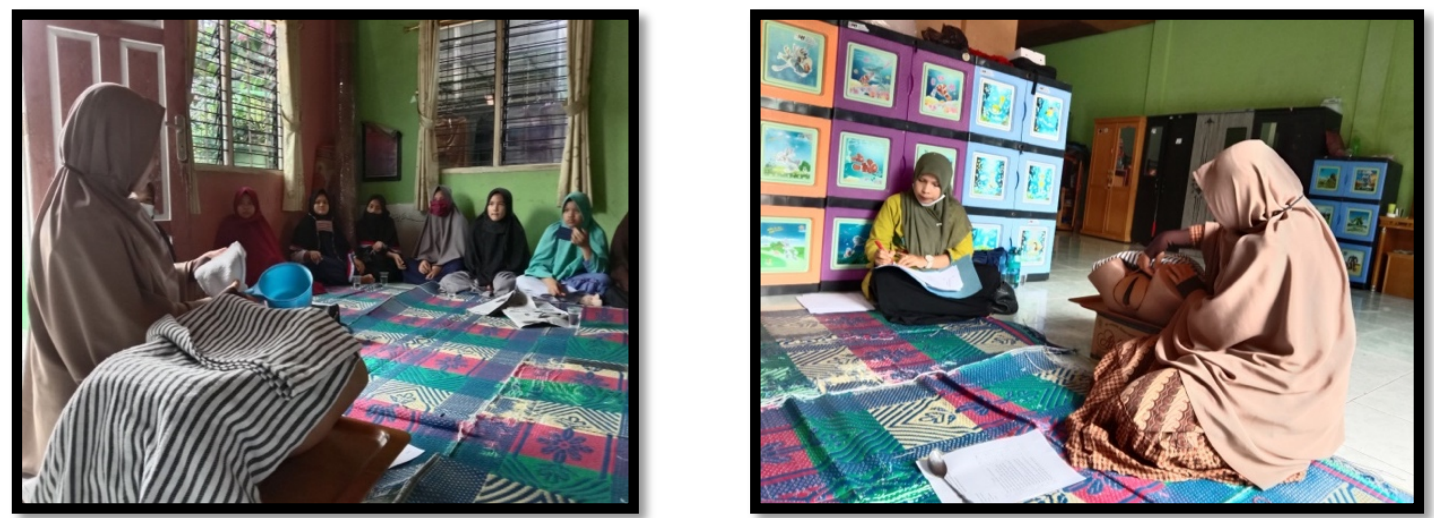

Gambar 6. Praktikum Personal Hygiene pada perempuan

6. Kegiatan Pembentukan dan Pelatihan Jacare. Pada kegiatan ini Tim PKM membentuk teman sebaya yang terdiri dari mahasiswa kesehatan sebanyak 2 orang yang berasal dari Prodi S1 Ilmu Kesehatan Masyarakat dan S1 Kebidanan dan Profesi Bidan. Pelatihan ini dilaksanakan di Kampus STIKes Payung Negeri Pekanbaru. Jacare ini melakukan pembinaan terkait kesehatan reproduksi remaja pada anak asuh di panti asuhan. Pelatihan ini bertujuan agar pengetahuan bertambah. Kepatuhan seseorang terhadap perlindungan diri dipengaruhi oleh pengetahuan yang dimiliki. [12]. Setelah Jacare ini diberikan pelatihan Peer Education (pendidikan sebaya) meliputi konsep, tujuan konseling remaja, komponen dalam konseling kesehatan remaja, proses konseling kesehatan remaja, masalah kesehatan reproduksi remaja, seks dan narkoba serta latihan tekhnik konseling.
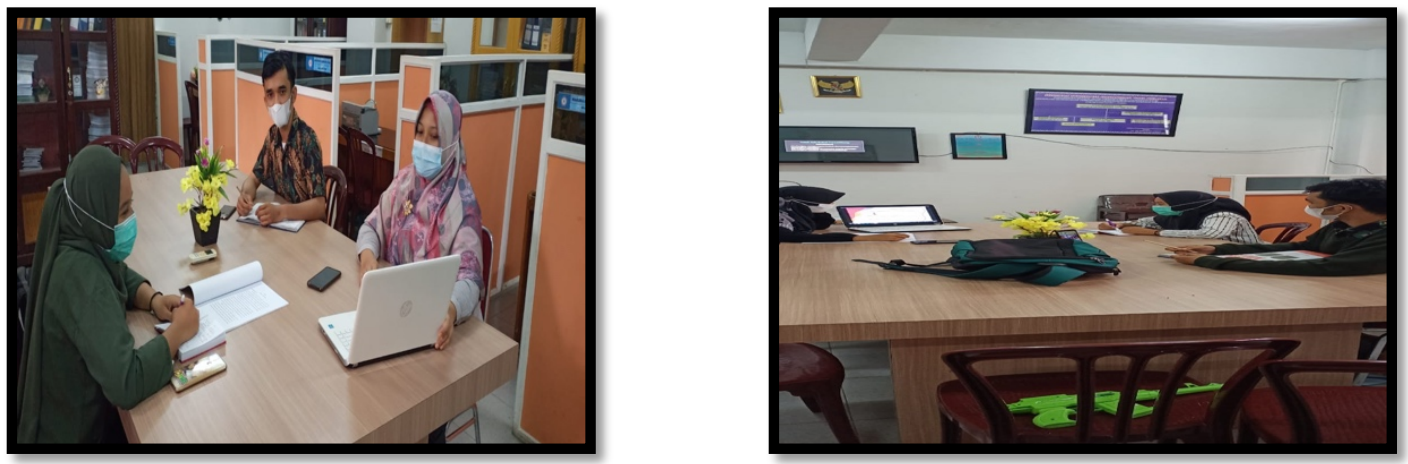

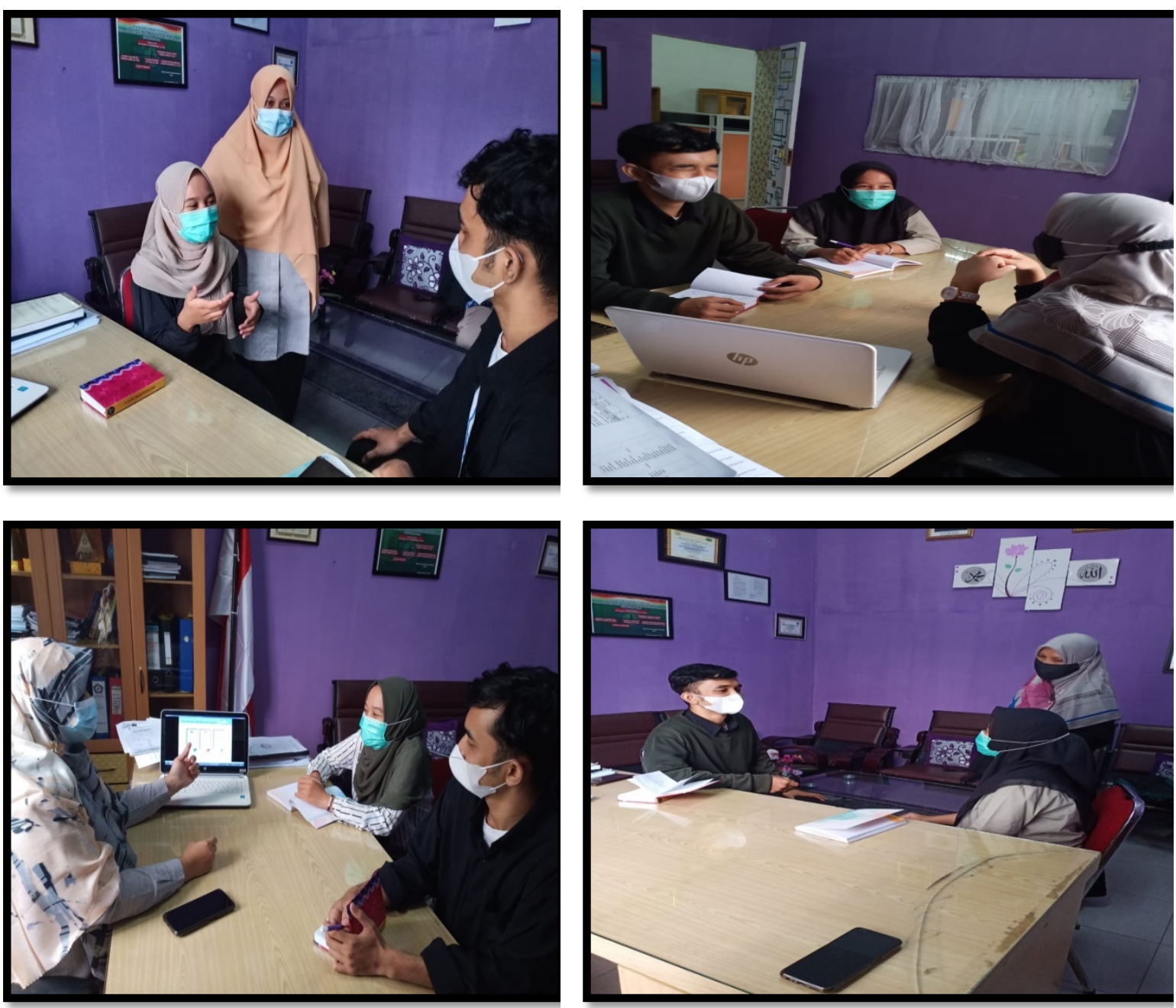

Gambar 7. latihan tekhnik konseling

Setelah pelatihan ini terlaksana, diperoleh hasil bahwa adanya peningkatan pengetahuan pada Jacare.

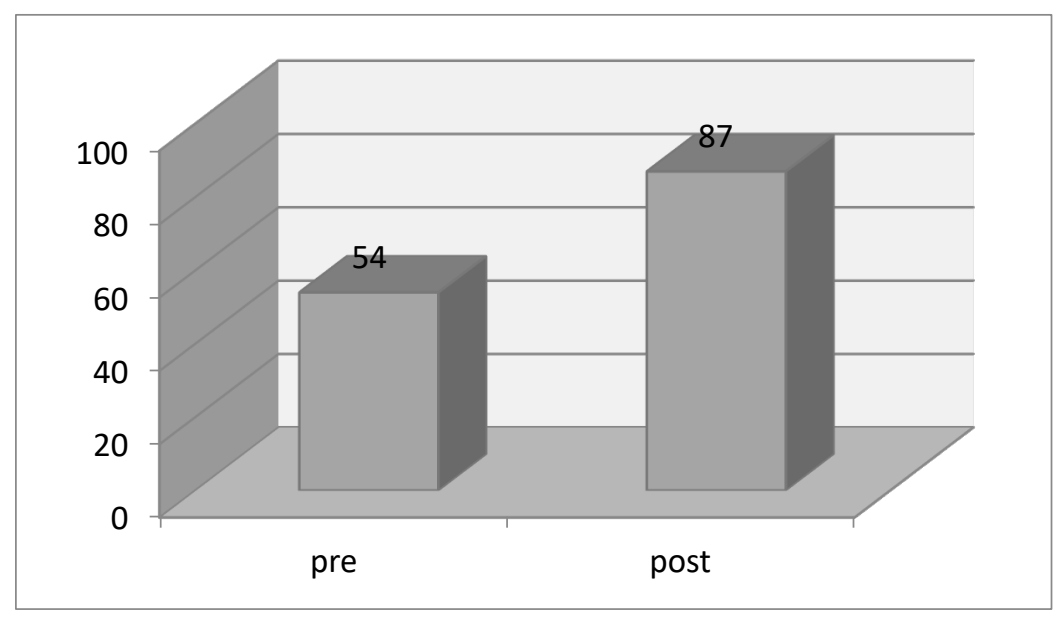

Gambar 8. Peningkatan pengetahuan mahasiswa setelah diberikan pelatihan Peer Education Di STIKes Payung Negeri Tahun 2021 
Dari gambar diatas terlihat peningkatan pengetahuan mahasiswa setelah diberikan pelatihan peer education sebesar 33\%, dimana dikelompokkan pada kategori cukup baik.

7. Pelaksanaan pendampingan. Pada kegiatan ini Remaja Care (Jacare) yang sudah dibentuk dan dilatih. Melakukan pendampingan terhadap anak asuh yang ada di panti. Dalam pelaksanaannya, 1 orang Jacare memiliki kewajiban untuk mendampingi 8-9 orang adek asuh. Adek asuhnya dikelompokkan berdasarkan jenis kelamin. Hal ini bertujuan agar pembahasan permasalahan dan penyelesaian masalah lebih mudah diatasi. Adek Asuh tersebut akan menjadi tanggung jawab Jacare dalam pembinaan seputar kesehatan reproduksi

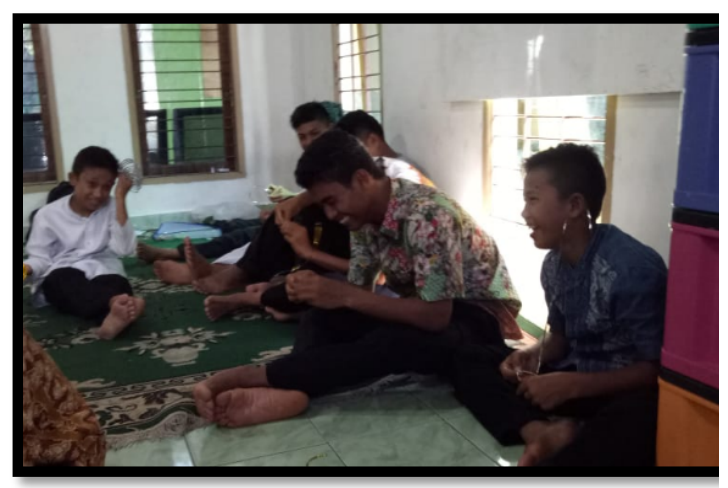

Pendampingan Jacare pada kelompok lakilaki

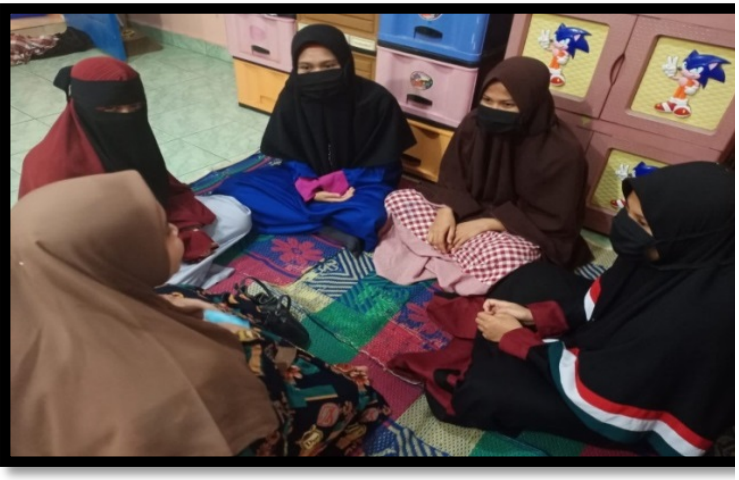

Pendampingan Jacare pada kelompok perempuan

\section{Gambar 8. Pendampingan Jacare pada kelompok laki-laki dan perempuan}

8. Evaluasi Kegiatan. Pada kegiatan ini Tim PKM melakukan evaluasi terhadap kegiatan yang telah dilakukan dengan cara melakukan post test pada anak asuh baik putra maupun putri untuk mengetahui pengetahuan dan keterapilan mereka setelah dilakukan penyuluhan dan praktikum tentang personal hygiene.
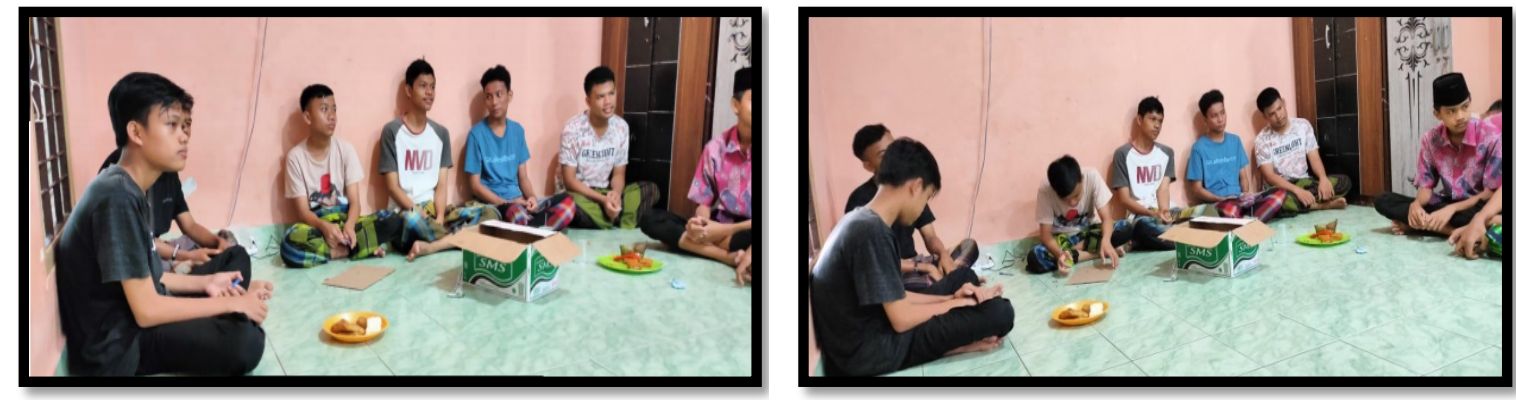

Gambar 9. Post Test pada anak laki-laki
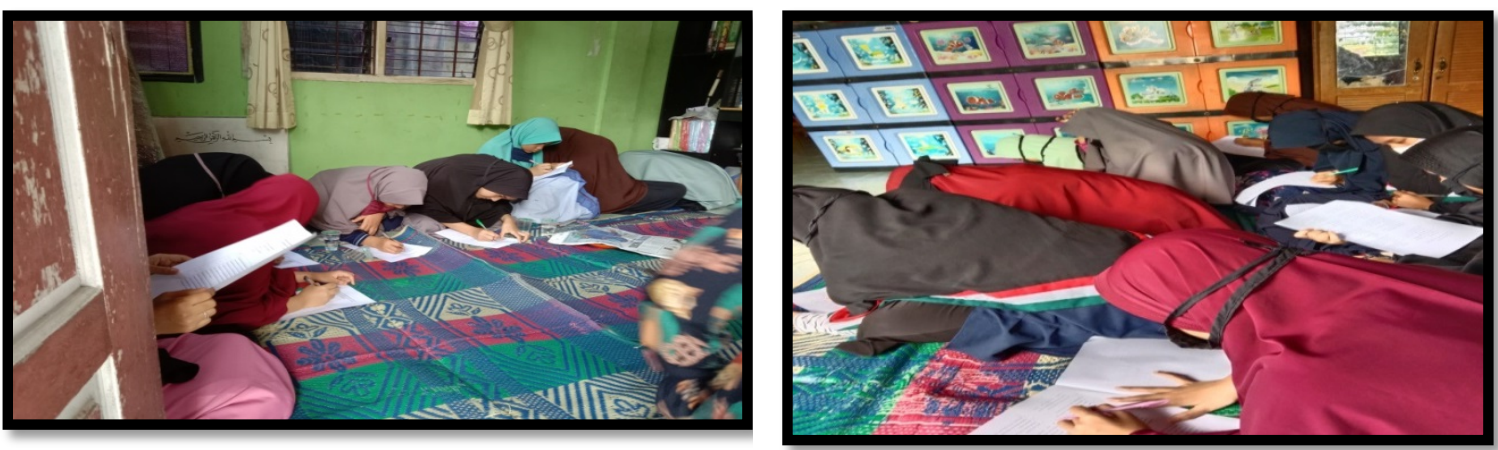

Gambar 10.Post Test pada anak perempuan 
Terjadi peningkatan pengetahuan anak asuh setelah dilakukan pelatihan, dimana pertamanya tidak tahu menjadi tahu. Peningkatan ini dapat dilihat dari hasil pretest dan posttest. Kegiatan pelatihan ini dilaksanakan melalui penyuluhan tentang konsep personal higiene, indikator kesehatan, cara pencegahan, perawatan diri serta penyakit seputar kesehatan reproduksi. Hasil peningkatan pengetahuan terlihat pada gambar 2 dibawah ini:

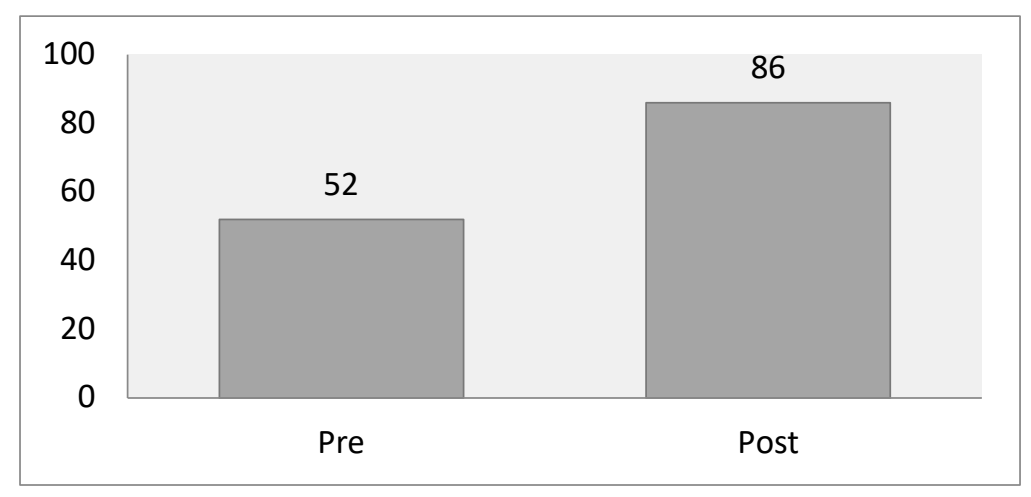

Gambar 11. Peningkatan pengetahuan setelah diberikan penyuluhan tentang Personal Higiene Pada Anak Asuh Di Panti Asuhan As-Salam Tahun 2021

Dari materi penyuluhan yang telah disampaikan tersebut diperoleh hasil bahwa terjadi peningkatan rata-rata pengetahuan setelah diberikan penyuluhan sebesar 34\%, dimana termasuk pada kategori cukup baik.

Setelah dilakukan praktikum kebersihan genitalia dan cara membersihkan gigi dengan menggunakan phantom (alat peraga), terjadi peningkatan keterampilan. Hasil peningkatan keterampilan anak asuh dapat dilihat pada gambar 3 berikut :

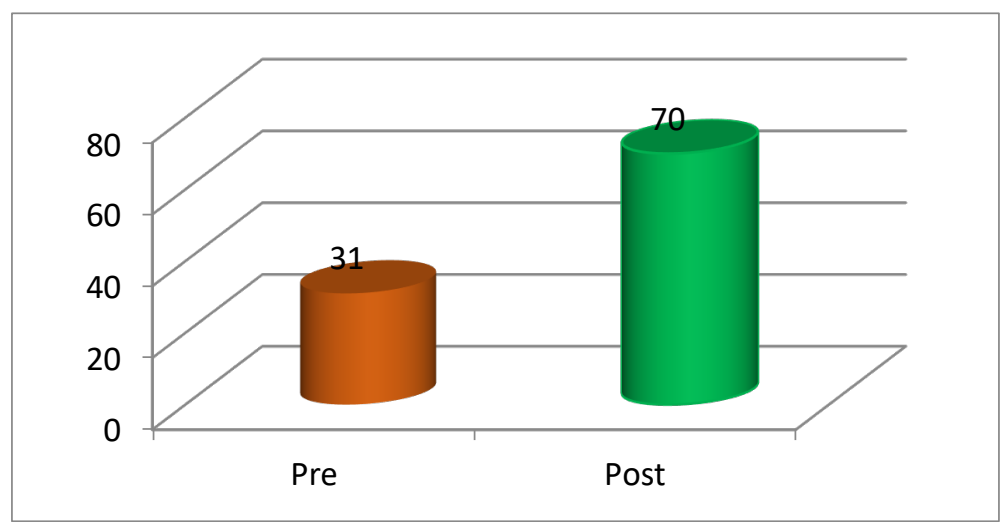

Gambar 12. Peningkatan keterampilan setelah diberikan praktikum tentang Kebersihan Genitalia dan Kebersihan Gigi Pada Anak Asuh Di Panti Asuhan As-Salam Tahun 2021 
Dari gambar 4 terlihat hasil bahwa terjadi peningkatan keterampilan setelah diberikan praktik menggunakan phantom adalah sebesar 39\%, pada kategori cukup baik.

Adapun lokasi kegiatan pengabdian masyarakat yaitu Panti asuhan As Salaam Nur Hidayah yang berada di J1 Safari Gg Safari IV Nomor 5 Kel Labuh baru Barat Kec Payung Sekaki Kota Pekanbaru. Lokasi Panti Asuhan As Salaam dapat dilihat melalui gambar peta berikut:
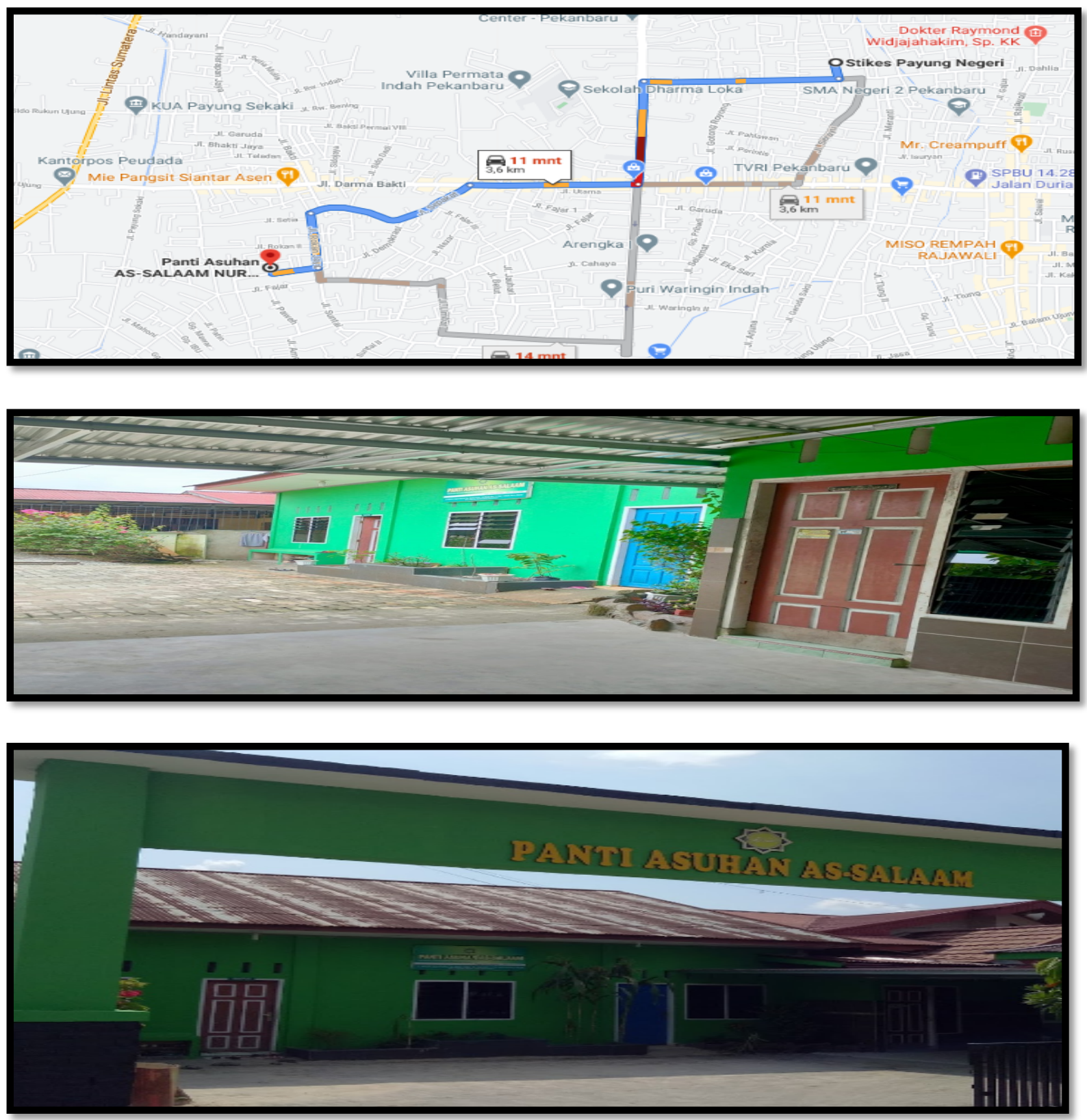

\section{KESIMPULAN}

Masa transisi yang dialami remaja membuat masalah yang dihadapi remaja sangat kompleks salah satunya berkaitan berkaitan dengan kesehatan reproduksi. Kurangnya pengetahuan remaja tentang kesehatan reproduksi mengakibatkan remaja sering terkena infeksi khususnya pada organ reproduksi. Masalah infeksi yang sering terjadi pada remaja timbul karena lingkungan yang kurang care terhadap masalah reproduksi yang dihadapi remaja serta pendidikan kesehatan reproduksi 
yang tidak didapatkan oleh remaja khususnya dari orang terdekat. Pemberian pendidikan kesehatan dan pembentukan kelompok belajar melalui pembentukan remaja care (Jacare) dilakukan sebagai sarana anak panti untuk mendapatkan lingkungan yang care dengan mereka. Dengan adanya kegiatan ini dapat meningkatkan pengetahuan dan keterampilan anak panti tentang kesehatan reproduksi khususnya berkaitan dengan personal hygiene dan narkoba. Tindak lanjut dari kegiatan PKM yaitu dengan tetap terus mengaktifkan pendampingan yang dilakukan oleh remaja care (Jacare) melalui whatsapp grop, dimana di whatsapp grop kelompok remaja care tetap memberikan informasi kepada adik-adik asuh dan melakukan diskusi disana tentang masalah yang mereka hadapi serta dicarikan solusi dari masalah tersebut. Untuk evaluasi dari pendampingan yang dilakukan melalui whatsapp grop Tim PKM beserta kelompok remaja care (Jacare) melakukan pertemuan tatap muka secara continue dan berkala setiap 6 bulan sekali untuk melihat peningkatan pengetahuan dan perubahan perilaku yang dialami anak panti selama pendampingan.

\section{DAFTAR PUSTAKA}

[1] A. . Syaifuddin, Ilmu Kebidanan Sarwono Prawirohardjo. PT Bina Pustaka Sarwono Prawirohardjo, 2016.

[2] L. Suryani, "Fakor-faktor Yang Mempengaruhi Perilaku Remaja Putri Tentang Personal Hgiene Pada Saat Menstruasi Di SMP Negeri 12 Kota Pekanbaru," J. Midwifery Sci., vol. 3, no. 2, pp. 68-79, 2019.

[3] S. W. S. Adkar, "Personal Hygiene Behavior of Butonese Adolescent Females during the Posuo Ritual in Baubau," vol. 1865, no. 4, pp. 52-58, 2019.

[4] H. . Talib, Adolescent gynecology., vol. 34, no. 1. Springer International Publishing, 2018.

[5] Kemenkes RI, "Situasi Kesehatan Reproduksi Remaja," Situasi Kesehatan Reproduksi Remaja, no. Remaja. p. 1, 2017.

[6] M. Abubakar, J. M. Ruru, And V. Y. Londa, "Efektivitas Program Konseling Remaja Di Dinas Pengendalian Penduduk Dan Keluarga Berencana Kota Manado," J. Adm. Publik, vol. 6, no. 94, pp. 1-7, 2000.

[7] G. F. Moore et al., "School, Peer and Family Relationships and Adolescent Substance Use, Subjective Wellbeing and Mental Health Symptoms in Wales: a Cross Sectional Study," Child Indic. Res., vol. 11, no. 6, pp. 1951-1965, 2018.

[8] Kementrian Kesehatan, "Tekhnik Konseling Kesehatan remaja bagi Konselor Remaja," 2010.

[9] L. Rochmawati and G. R. Rahayu, "The effectiveness of peer education on personal hygiene behavior among students in pesantren boarding school," Ber. Kedokt. Masy., vol. 33, no. 11, pp. 541-546, 2017.

[10] A. Purba, E. Kartika, and D. R. Bancin, "Pembinaan Kelompok Remaja Melalui Edukasi \& Peer Educators Kesehatan Reproduksi Di Desa Tanjung Rejo," MONSU'ANI TANO J. Pengabdi. Masy., vol. 3, no. 1, pp. 1-8, 2020.

[11] Sarmin, "Konselor Sebaya: Pemberdayaan Teman Sebaya Dalam Sekolah Guna Menanggulangi Pengaruh Negatif Lingkungan," Briliant, J. Ris. dan Konseptual, vol. 2, pp. 102-112, 2017.

[12] I. D. Pardosi and D. S. Aryantiningsih, "Analisis Pelatihan, Motivasi, Ketersediaan Alat Dan Pengawasan Penggunaan Apd Pada Laboran Tb Di Puskesmas Kota Pekanbaru," Health Care (Don. Mills)., vol. 8, no. 1, pp. 30-38, 2019. 